Article

\title{
Investor Attention and Stock Market Activities: New Evidence from Panel Data
}

\author{
Chaiyuth Padungsaksawasdi ${ }^{1, *}$, Sirimon Treepongkaruna ${ }^{2}$ and Robert Brooks ${ }^{3}$ \\ 1 Thammasat Business School, Department of Finance, Thammasat University, Bangkok 10200, Thailand \\ 2 University of Western Australia Business School, Accounting and Finance, The University of Western \\ Australia, 6009 Perth, Australia; sirimon.treepongkaruna@uwa.edu.au \\ 3 Monash Business School, Department of Econometrics and Business Statistics, Monash University, \\ Clayton VIC 3800, Australia; robert.brooks@monash.edu \\ * Correspondence: chaiyuth@tbs.tu.ac.th
}

Received: 11 May 2019; Accepted: 10 June 2019; Published: 12 June 2019

\begin{abstract}
Using the panel vector autoregression (VAR) method, this paper documents relationships between investor attention and stock market activities; i.e., return, volatility, and trading volume, respectively. In sum, bidirectional dynamic interdependence of the SVI-stock market activities relationship exists, in which the SVI-trading volume relationship shows the strongest evidence. This is consistent with prior literature using trading volume as a proxy of investor attention. However, the relationships in the developed and developing markets are statistically significantly different. The stock markets in the developed markets over-react more to the search volume than those in the developing markets. We postulate that investor attention is one of the key elements in asset pricing in stock markets.
\end{abstract}

Keywords: investor attention; Google SVI; panel VAR; stock index activities; Pacific-basin countries

JEL Classification: G400; G14; G15

\section{Introduction}

Differences in cross-sectional and time-varying investor attention are important components for improving the quality of investment decision-making, as well as for supporting the economic aggregates (Jacobs 2015), though attention is a scarce cognitive resource (Kahneman 1973). Investors have attention constraints that limit their ability to analyze all available information arriving to equity markets, thus they focus only on information of their immediate interests. This in turn suggests that investor attention should be related to activities in the markets. For example, DellaVigna and Pollet (2009) show the Friday inattention effect, in which stock prices on Friday earnings announcements show a larger drift and a slower response than the other days. Seminal works on investor attention at the country level show that investor attention measured by the Google SVI ${ }^{1}$ influences stock market activities such as return (Da et al. 2011 and Tantaopas et al. 2016), volatility (Dimpfl and Jank 2016; and Andrei and Hasler 2015), trading volume (Takeda and Wakao 2014), and liquidity (Ding and Hou 2015), respectively. ${ }^{2}$ These findings provide support for a potential of interrelations between investor

1 The survey study in New Zealand of Tourani-Rad and Kirkby (2005) shows that almost half of the respondents actively uses the internet as a source of information for making decision in the investment, which is subject to the psychological bias (investor socialization). Recently, Laksomya et al. (2018) show an impact of message board posted on internet on price manipulation in the stock exchange of Thailand.

2 It should also be noted that the Google SVI has also been used to capture retail investor attention in other markets such as foreign exchange and real estate markets. For example, Yung and Nafar (2017) document high search-intensity REITs possess 
attention and stock market activities, including predictability. However, at present, there exists no empirical evidence to demonstrate whether investor attention causes stock market returns, stock market volatility, and stock market trading volume, respectively, or vice versa in a cross-country analysis.

Even though prior literature shows the attention-stock market activities association in a number of countries, ${ }^{3}$ Tantaopas et al. (2016) note that the level of investor attention is potentially affected by the shareholder base, culture, ownership structure, legal protection, law enforcement, and financial education, respectively. These characteristics are unique for an individual country. Thus, from a bird's eye view, studying on an individual country basis might not show comprehensive findings on the attention effect in stock markets. It is likely that each fixed effect factor in each country influences the attention-market activities relationship differently. We question whether prior findings in each country are driven by an influence of these unobservable fixed effects. This research aims to fill the gap in this regard.

This paper contributes to prior literature in four main areas shedding light on the role of investor attention in stock markets. First, this study is the first to examine the dynamic attention-stock market activities relationship using the panel vector autoregression (VAR) model. Studies of the attention effect on time series data of an individual stock market potentially lead to conclusions that are subject to a selected country. Thus, the panel VAR is superior to other methodologies by taking into account of the effect of both cross-section (i.e., unobservable fixed effect factors) and time series. Second, we add to existing literature by directly comparing and discussing our results in terms of potential differences in the attention-stock market activities relationships between developed and developing countries. Investors in each country might react differently due to a limited attention. Third, our results highlight the significant role of investor attention in financial markets by documenting the relationship of the level of attention and stock market activities at the aggregate level (panel data) and the predictive power of these activities. Last, we reaffirm that the attention effect is an international phenomenon that is not evidenced in a particular country.

As in Grossmann et al. (2014), we apply the panel VAR for our cross-country analysis. Some beneficial issues of using panel VAR distinguish our paper from prior studies. First, the concept of VAR is an appropriate technique for a general setup, such as the relationship of investor attention and stock market activities as presented in this paper. Second, both fixed and time-varying effects are taken into consideration under the panel VAR specification. Thus, our results are not biased from a time-invariant unobserved heterogeneous factor as well as a time-varying unobservable factor. Last, we can apply the panel VAR with a relatively short data period. The panel VAR technique takes both cross-sectional and intertemporal data in the computation, which increases the number of observations and subsequently helps improve the quality of parameter estimations.

We employ the panel VAR to investigate the relationship between the Google SVI and stock market activities. Throughout the study, we separate our analyses into three categories, the full sample, the developed countries, and the developing countries, respectively. The data includes ten countries in the Asia-Pacific region as in Tantaopas et al. (2016) because we would like to show, compare, and contrast our results on panel data with the results of individual country analyses. Our results in this study strengthen the importance of archival finance research in the Asia-Pacific Basin suggested by Benson et al. (2014). Mostly, two-way panel Granger causality dynamic relationships between the investor attention and each stock market activity exist, especially for the attention-trading volume relationship that we observe in all categories. We conjecture that investor attention, as a behavioral factor, is one of the key determinants in stock markets regardless of the effects of unique

high expected returns and the search query is important, especially for small stocks, high book-to-market stocks, and less informative stocks. In foreign exchange markets, Goddard et al. (2015), show the co-movement between the Google search intensity and volatilities in major currencies, and conjecture that investor attention is a risk factor in the FOREX markets.

3 For example, see Aouadi et al. (2013) for France, Bank et al. (2011) for Germany, Ying et al. (2015) for China, Takeda and Wakao (2014) for Japan, Tantaopas et al. (2016) for the Asia-Pacific countries, and Da et al. (2011) for the U.S. 
characteristics (fixed effect) in each country sample, showing that limited investor attention violates the efficient market hypothesis. However, among three attention-stock market activity relationships, only the attention-trading volume relationship is statistically significant for the developing markets. We postulate that search by individuals causes excessive trading volumes in stock markets and vice versa, though the impact of the volume to the investor attention seems to be less. This evidence supports that attention is primarily related to abnormal trading volume and is consistent with prominent literature using trading volume as a proxy of attention ${ }^{4}$ (Barber and Odean 2008 and Gervais et al. 2001), We infer that the correlation between trading volume and attention should be notably high. It is interesting to note that we observe a one-way causality relationship of the investor attention in the full sample and weak impacts of the volume to the investor attention in the developed and developing countries. In general, people might gather information before they trade. However, when trading volume is high, investors do not gather more information to trade on fundamentals, rather herd behavior is dominant. Focusing on the results of the other two relationships in the developing countries, we find that investors in these countries do not search for information when they trade stocks.

For the panel VAR estimations, most results are in general consistent with the panel Granger causality. The attention-return relationship is significantly negative with the effect of the return on the SVI stronger than the other way around. Negative events catch more attention than positive ones, implying that investors concern more on the downside risk (Ang et al. 2006). In contrast, the attention-volatility relationship is positive and significant. The impact of the volatility on the SVI is shorter-lived and greater in magnitude than that of the SVI on the volatility. Swing movements in the market catch more attention. Dimpfl and Jank (2016) support our findings by showing the co-movement of the DJIA search keyword and its realized volatility during July 2006 to December 2011. They find that the search query is higher than the average during the turbulent period. Thus, searching behavior is time-varying. In addition, we cannot neglect the important role of trading volume on the higher moments of the stock return distribution as suggested by Do et al. (2014). In the study the attention-abnormal trading volume relationship has the strongest results with relatively higher numbers of statistically significant coefficients for all samples in our analysis. However, the impact of the trading volume is mixed, as the sign shows both negative and positive relationships. We find that the relationship between SVI and abnormal trading volume is negative for a window of the previous two weeks, but reverses to be positive for a window of the past week. The intuition of the positive relationship is straightforward; when investors pay attention to stocks, they are likely to trade them. The higher the investor attention, the larger the trading volume, and vice versa. Our findings seem to make intuitive sense in that information in the further past (e.g., previous two weeks) is already priced, as such investors do not search for any information. However, information asymmetry in a more recent past (e.g., previous one week) is relatively high, leading to an increase in search volume.

All orthogonalized impulse response functions depict similar patterns to the panel VAR results. A comparison of the attention effect between the developing and developed markets indicates significant differences between the two groups. We conclude that the investor attention is common in equity markets, albeit the impact (both the magnitude and number of statistically significant coefficients) is larger in the developed markets. A possible explanation of these differences is that the equity markets in the developed countries over-react more to the level of investor attention than are those in the developing countries. The under-reaction in the developing markets is explained by the frog-in-the-pan hypothesis (Da et al. 2014), stating that investors under-react when small amounts of information arrive to the market relative to large amounts of information arrival. These findings reconfirm the arguments proposed in Tantaopas et al. (2016) that the level of investor attention could

4 Barber and Odean (2008) argue that without investor attention, trading volume cannot happen. Thus, trading volume is a consequence of actual attention. 
be impacted by the shareholder base, culture, ownership structure, legal protection, law enforcement, and financial education.

\section{Relevant Literature}

The efficient market hypothesis shows when information arrives in the market, investors can receive, analyze, and decide to trade securities without limited time, limited processing resources, and limited attention. Thus, asset prices change immediately and appropriately, driving to rational trading. However, psychological research ${ }^{5}$ suggests that investors have limited attention that they can utilize and so focus on information of their interests within a given period. Investor attention and stock markets then co-move over time (Peng et al. 2007). Investor attention is traditionally proxied by either news and headlines, trading volume, advertising expenses, or ceiling price, however each of these measures has drawbacks. Recently, research on the impact of investor attention in financial markets ${ }^{6}$ has gained interests from scholars and the Google SVI is widely used as a reliable and direct proxy of retail investor attention. This is consistent to Benson et al. (2014), who conjecture that behavioral explanation in stock market activities have gained popularity in Asia-Pacific Basin journals.

Merton (1987) shows that investors will trade a stock as far as they recognize it. Consequently, Huberman and Regev (2001) and Barber and Odean (2008) suggest when information arrives in the market, only attention from investors causes changes in prices, implying that investor attention is a necessary condition of stock trading. Thus, investor attention is the key of investors' decision-making. This is consistent with Da et al. (2011), documenting that investor attention influences stock movement and is not constant over time. High and low levels of investor attention affect the reaction of the stock market differently. ${ }^{7}$ A high level of investor attention causes a pressure to stock prices and drives the prices to be efficient, while investors under-react when they pay less attention. In fact, researchers provide evidence of the relationship of investor attention and financial market activities in terms of both individual securities and the aggregate market level. Recently, Tsukioka et al. (2017) using textual analysis to extract related investor sentiment words, show that high levels of investor attention and investor sentiment help explain IPO puzzles in the Japanese market. Another example of the effect of internet message boards on price manipulation in the Thai stock market is investigated by Laksomya et al. (2018). In general, the results of the firm-level data are not qualitatively different from those of the market-wide level in that there exists a relationship between investor attention and stock market activities. For example, Bijl et al. (2016) document the negative return predictability of the Google SVI in the S\&P 500 companies, which contradicts Da et al. (2011) and Joseph et al. (2011), who suggest a positive predictive power of the Google SVI on stock returns. In sum, we cannot avoid the effect of the internet's power in financial markets.

However, Vozlyublennaia (2014) and Tantaopas et al. (2016) document that the Google SVI should be tested with a country-wide investment. We thus limit our discussion in this section only on existing evidence of the aggregate level, which is consistent with the aim and the scope of this study. Importantly, not many studies conduct research on the aggregate level of stock performance, stock volatility, and stock trading volume in a single study. Our research thus provides such additional evidence.

Evidence regarding investor attention has remained mixed, as to whether it strengthens or worsens market efficiency. On the supporting side, Vozlyublennaia (2014) shows the dynamic interrelationship of investor attention and aggregate market activities in several asset classes in the U.S. markets. Moreover, the presence of investor attention helps improve return efficiency. An increase in attention

5 Two other popular behavioral factors influencing stock market activities include investor mood (Harding and He 2016) and investor sentiment (Piccoli et al. 2018 and Johnman et al. 2018).

6 The study of the attention effect is not limited only in stock markets and the results in other markets largely confirm the findings in stock markets. See, for example, Goddard et al. (2015) for foreign exchange markets, Li et al. (2015) for energy markets, and Rochdi and Dietzel (2015) and Braun (2016) for real estate markets.

7 An asymmetric impact of the investor attention is similar to that of the investor sentiment. Tsai (2017) demonstrates that pessimistic investor sentiment spreads over more than optimistic investor sentiment, confirming the asymmetry. 
reveals information to asset prices. $^{8}$ Hamid and Heiden (2015) confirm this in terms of volatility predictability, and document that investor attention drives the Dow Jones equity index to be more efficient both in- and out-of-sample and especially in the high volatile state. Moreover, Tantaopas et al. (2016) extend prior studies by examining the investor attention effect both in developing and developed countries. The attention diminishes return and volatility predictability, consistent with the information discovery hypothesis. However, they do find an ceffect on trading volume predictability.

On the opposing side, Dimpfl and Jank (2016) find the contemporaneous co-movement between the Dow Jones' search volume intensity and realized volatility. Moreover, search volume increases the volatility predictability, consistent with the noise trader hypothesis. Keyword search by retail investors is considered as uninformed noise traders and causes the market to become more volatile.

In summary, existing literature is largely based on evidence on individual countries in advanced economies, especially in the U.S. markets and the results are still inconclusive. This paper fills a considerable gap in this field providing new evidence on the cross-country analysis based on an international perspective, considering developing countries, and developed countries, respectively.

\section{Data}

\subsection{Google Search Intensity}

We analyzed selected search keywords obtained by Google Trends ${ }^{9}$ in this study following the approach adopted by Tantaopas et al. (2016). Our sample for analysis consisted of ten countries categorized into two subsamples, developing (China, ${ }^{10}$ India, Malaysia, and Thailand) and developed markets (Australia, Hong Kong, Japan, Korea, New Zealand, and Singapore). We decided to employ the same country sample for a direct comparison. Moreover, we shed light on additional evidence of the index performances rather than on individual stocks as suggested by Vozlyublennaia (2014). The search keywords employed in this study are shown in the Appendix A. ${ }^{11}$ Other stock markets data were from DataStream. Our sample spanned the time period from January 2004 to December 2014.

\subsection{Stock Market Return, Volatility, and Abnormal Trading Volume}

In this study Google's weekly SVI starts on Sundays and is shown in terms of a natural logarithm. Weekly stock index returns $(R)$ in each country are calculated as the natural logarithm of closing stock market index price changes on Mondays and Fridays during the same week. Weekly stock index return volatility $\left(\sigma^{2}\right)$ in each country is the weekly squared return from Mondays to Fridays during the same

8 Storms et al. (2015) also document the efficiency-improving role of investor attention in individual stocks in the European and the U.S. markets. The efficiency improvement is more pronounced during bullish markets. Aouadi et al. (2013) find the same evidence in the French stock market.

9 From the Google Trends' website, we select the "global region" in order to capture the "true" investor attention around the globe.

10 Even though some employ the Baidu search engine rather than Google search engine in the mainland Chinese stock market due to the exit of the Google on March 23, 2010, we prefer using the Google SVI for a few reasons. First, uses of the same international search engine for all countries make the data consistent and comparable. Our approach is similar to Gao et al. (2016), who study the Google sentiment on stock markets in a cross country analysis around the globe, including mainland China. Second, though Google search is prohibited in the mainland China, foreign retail investors are still able to use Google to search information and decide to trade in the Chinese stock markets or local investor can use the virtual private networks (VPNs) to access the Google website (Wang et al. 2017). Thus, Google search intensity for the Chinese stock market is valid.

11 The search keywords are in the English language. There are some working papers that use the local language for the search queries. For example, Storms et al. (2015) rely on the search keywords in local languages for stocks in European countries. However, they show that the local search keywords are highly correlated with the English search keywords. Thus, the search keyword is not biased from the choice of the languages. The results are similar to the findings of Al-Eroud et al. (2011), who study the language preferences for searching Google queries for Arab countries. The internet users in these countries favor to use English language rather than their own local languages to Google search. Thus, our use of English search keywords in the study is in line with other literature. 
week. We follow Takeda and Wakao (2014) to define abnormal trading volume (ATV) in each stock market $i$ as below.

$$
A T V_{i, t}=\frac{T V_{i, t}-\overline{T V_{i}}}{\overline{T V_{i}}}
$$

where $T V_{i, t}$ is natural logarithm of trading volume of the stock market $i$ during week $t . \overline{T V_{i}}$ is the average trading volume of stock market $i$ over the entire sample period.

\section{Panel Vector Autoregression}

Prior literature shows that SVI and other markets variables possess dynamic interrelationships. In a reduced form, the VAR for panel data is presented as:

$$
\left[\begin{array}{c}
S V I_{i, t} \\
Y_{i, t}
\end{array}\right]=\left[\begin{array}{ll}
a_{11} & b_{11} \\
a_{21} & b_{21}
\end{array}\right]\left[\begin{array}{c}
S V I_{i, t-1} \\
Y_{i, t-1}
\end{array}\right]+\left[\begin{array}{cc}
a_{12} & b_{12} \\
a_{22} & b_{22}
\end{array}\right]\left[\begin{array}{c}
S V I_{i, t-2} \\
Y_{i, t-2}
\end{array}\right]+\cdots+\left[\begin{array}{cc}
a_{1 p} & b_{1 p} \\
a_{2 p} & b_{2 p}
\end{array}\right]\left[\begin{array}{c}
S V I_{i, t-p} \\
Y_{i, t-p}
\end{array}\right]+\left[\begin{array}{c}
f_{1 i} \\
f_{2 i}
\end{array}\right]+\left[\begin{array}{c}
e_{1 i, t} \\
e_{2 i, t}
\end{array}\right]
$$

where $S V I_{i, t}$ is the appropriate selected keyword of the stock market index in country $i$ in week t. $Y$ represents the stock market variables; namely stock market index return, stock market return volatility, and stock market abnormal trading volume. $i$ represents ten countries, which are divided into two groups, developing markets (China, India, Malaysia, and Thailand) and developed markets (Australia, Hong Kong, Japan, Korea, New Zealand, and Singapore). $p$ is the optimal lag length suggested by Andrews and Lu (2001), which is equal to one in the SVI-return relationship and two in the SVI-volatility, and the SVI-abnormal trading volume relationships, respectively. Andrews and Lu (2001) developed a new methodology for the model selection procedures known as the consistent model and moment selection criteria (MMSC), which is based on GMM estimation. Their proposed technique is similar, but superior, to maximum likelihood estimation used in the Akaike information criteria (AIC), the Bayesian information (BIC), and Hannan-Quinn information criteria (HQIC), respectively. A consensus of the minimum lag length of MMSC-AIC, MMSC-BIC, and MMSC-HQIC was the criterion for the model selection in this study.

In panel data, we might encounter some individual heterogeneity. $f_{i}$ represents a fixed effect in the model, thus unobservable factors in each country are not time-variant. It is common and essential to control for the country's fixed effect in a panel analysis. However, incorporating unobservable country's fixed effect variables in the model induces a correlation among independent variables because of the lagged values of the dependent variables. A common use of first-differencing procedure for solving this problem yields biased and inconsistent estimated coefficients. This might cause more missing data in an unbalanced panel. We alleviated this potential problem by taking a forward mean-differencing procedure known as the Helmert transformation procedure or forward orthogonal deviation (Arellano and Bover 1995). This procedure eliminates the fixed effect of the model by transforming all variables in terms of differences from forward means, subsequently reducing missing data. Hayakawa (2009) addresses the choice of transformation that is of concern in GMM estimation of a finite sample for empirics and shows that the first difference transformation method is inferior to the forward orthogonal deviation transformation method. Thus, a new panel VAR model after Helmert transformation $(H)$ is:

$$
\left[\begin{array}{c}
S V I_{i, t}^{H} \\
Y_{i, t}^{H}
\end{array}\right]=\left[\begin{array}{ll}
a_{11} & b_{11} \\
a_{21} & b_{21}
\end{array}\right]\left[\begin{array}{c}
S V I_{i, t-1}^{H} \\
Y_{i, t-1}^{H}
\end{array}\right]+\left[\begin{array}{ll}
a_{12} & b_{12} \\
a_{22} & b_{22}
\end{array}\right]\left[\begin{array}{c}
S V I_{i, t-2}^{H} \\
Y_{i, t-2}^{H}
\end{array}\right]+\cdots+\left[\begin{array}{ll}
a_{1 p} & b_{1 p} \\
a_{2 p} & b_{2 p}
\end{array}\right]\left[\begin{array}{c}
S V I_{i, t-p}^{H} \\
Y_{i, t-p}^{H}
\end{array}\right]+\left[\begin{array}{c}
v_{1 i, t} \\
v_{2 i, t}
\end{array}\right]
$$

Because of dynamic interrelationships among the SVI, stock market variables, and the fixed effect, the estimation of the least squares dummy variable procedure (LSDV) yields biased estimated coefficients (Rousseau and Wachtel 2000). A new panel VAR model using GMM estimation was a more appropriate technique in this study for the causality relationships (see for example, Love and Zicchino 2006 and Grossmann et al. 2014). We follow the GMM estimation proposed by Holtz-Eakin et al. (1988). 
For our panel VAR analysis, we ran pairwise relationships between the SVI and stock market index return, the SVI and stock market volatility, and the SVI and stock market abnormal trading volume, respectively.

\section{Empirical Results}

The stationarity for all variables for panel data was confirmed by using Fisher-type unit root test based on Augmented Dickey Fuller (ADF) and Philips-Perron (PP) statistics as suggested by Choi (2001). ${ }^{12}$ For all analyses, we present our results in three panels, i.e., Panel A for the relationship between the SVI and stock market index return (SVI-return), Panel B for the relationship between the SVI and stock market volatility (SVI-volatility), and Panel C for the relationship between the SVI and stock market abnormal trading volume (SVI-volume). Moreover, we separated our sample into three categories for in-depth analyses: (i) full sample, (ii) developed markets (Australia, Hong Kong, Japan, Korea, New Zealand, and Singapore), and (iii) developing markets (China, India, Malaysia, and Thailand). Overall, we present, compare, and discuss our results both in terms of types of the relationships and those of market developments.

\subsection{Panel Granger Causality}

Table 1 shows the panel Granger causality tests for the SVI-return, the SVI-volatility, and the SVI-abnormal trading volume. Overall, two-way relationships existed in most cases. ${ }^{13}$ This was consistent with the information discovery hypothesis, indicating that the SVI and each market activity hold interdependence relationships. However, evidence in the developing markets was weakest, such that we did not find any causality relationship of the SVI-return and the SVI-volatility. This was consistent with Tsai (2017), who finds mostly no Granger causality relationship between the Kumar and Lee (2006) sentiment index of different types of institutional traders and stock market returns in the Taiwanese stock exchange. Our findings on broad market activity contradict the results of the experimental design by Boduroglu et al. (2009) that Westerners allocate their attention in a narrower manner than East Asians. Interestingly, the evidence of two-way interdependence relationships was very strong; significant SVI-volume relationships existed in all cases. This finding is consistent with Miller (1977) and Gervais et al. (2001), who document that trading volume attracts investor attention and encourage markets participants to buy stocks. Thus, the larger the trading volume, the higher the investor attention. In general, our results are consistent with Tantaopas et al. (2016), who investigate the attention effect in individual countries. However, our evidence in the developing countries appears weaker.

\subsection{Panel Vector Autoregression}

In this section, we assess the causal relationships through panel VAR using GMM estimation as presented in Table 2. We confirmed our model identification by employing Hansen's J-statistic test. The null hypothesis of the test was not rejected; hence, the model estimation was valid. Overall, the results were consistent with our findings from the panel Granger causality analysis. Panel A of Table 2 shows the two-way relationship for the full sample and the one-way SVI-return relationship for the developed markets. In general, the relationship was negative and the effect of the return on the SVI was greater than that of the SVI on the return. For the full sample, the magnitude of negative lagged

12 The null hypothesis is that panels are unit roots. The $Z$ statistic is presented as $Z=\frac{1}{\sqrt{N}} \sum_{i=1}^{N} \Phi^{-1}\left(p_{i}\right)$, where $p_{i}$ is the $i$ th panel and $\Phi^{-1}$ is the inverse of the standard normal cumulative distribution function. $Z$ is normally distributed with zero mean and unity variance. The results are available upon request.

13 It is interesting to note that one-way relationships are detected in the SVI-volatility relationship of the developed markets and the SVI-volume relationship of the full sample. SVI Granger causes stock market volatility and abnormal trading volume, but not the other way around. When people search more they are making the market more volatile or executing more trade orders. Thus, Google search intensity is a good proxy of retail investor attention. 
returns on the current SVI (1.8397) was larger than the impact of the negative lagged SVI on the current returns (0.0035). However, only negative lagged returns influenced the current SVI for the developed markets. We argue that people searched more for information after a crash in equity markets in those countries. Interestingly, we did not observe this relationship for the developing markets. We propose possible explanations as follows. First, investors in the developing markets do not search information via search engines. The number of non-users internet relative to the population in developing countries is much greater than that of developed countries. ${ }^{14}$ Alternatively, technological advance in developing countries is less than that of developed countries. Second, Nisbett et al. (2001) show that Asians are less analytic, less rational, and more holistic than Westerners, the considerable social differences affect people's belief and cognitive processes. Chang et al. (2000) show that herd behavior is strongly apparent in developing markets, but not in developed markets. Moreover, herd behavior in developing markets is more asymmetric than in developed markets, especially in up markets (Chiang and Zheng 2010).

Table 1. Panel Granger causality.

\begin{tabular}{|c|c|c|}
\hline & Chi-Square & $p$-Value \\
\hline \multicolumn{3}{|l|}{ Panel A: SVI and Return } \\
\hline \multicolumn{3}{|l|}{ Full Sample } \\
\hline SVI does not Granger cause return & $3.847^{* *}$ & 0.050 \\
\hline Return does not Granger cause SVI & $6.312 * *$ & 0.012 \\
\hline \multicolumn{3}{|l|}{ Developed markets } \\
\hline SVI does not Granger cause return & $3.092 *$ & 0.079 \\
\hline Return does not Granger cause SVI & $5.35^{* *}$ & 0.021 \\
\hline \multicolumn{3}{|l|}{ Developing markets } \\
\hline SVI does not Granger cause return & 0.004 & 0.947 \\
\hline Return does not Granger cause SVI & 0.992 & 0.319 \\
\hline \multicolumn{3}{|l|}{ Panel B: SVI and Volatility } \\
\hline \multicolumn{3}{|l|}{ Full Sample } \\
\hline SVI does not Granger cause volatility & $7.674^{* *}$ & 0.022 \\
\hline Volatility does not Granger cause SVI & $4.901 *$ & 0.086 \\
\hline \multicolumn{3}{|l|}{ Developed markets } \\
\hline SVI does not Granger cause volatility & $15.695^{* * *}$ & 0.000 \\
\hline Volatility does not Granger cause SVI & 1.249 & 0.536 \\
\hline \multicolumn{3}{|l|}{ Developing markets } \\
\hline SVI does not Granger cause volatility & 2.201 & 0.333 \\
\hline Volatility does not Granger cause SVI & 2.954 & 0.228 \\
\hline \multicolumn{3}{|l|}{ Panel C: SVI and Abnormal Trading Volume } \\
\hline \multicolumn{3}{|l|}{ Full Sample } \\
\hline SVI does not Granger cause volume & $414.089 * * *$ & 0.000 \\
\hline Volume does not Granger cause SVI & 1.362 & 0.506 \\
\hline \multicolumn{3}{|l|}{ Developed markets } \\
\hline SVI does not Granger cause volume & $28.301 * * *$ & 0.000 \\
\hline Volume does not Granger cause SVI & $5.222 *$ & 0.073 \\
\hline \multicolumn{3}{|l|}{ Developing markets } \\
\hline SVI does not Granger cause volume & $268.509 * * *$ & 0.000 \\
\hline Volume does not Granger cause SVI & $4.648 *$ & 0.098 \\
\hline
\end{tabular}

Table 1 shows the results of the panel Granger causality test for three relationships. Panels A to $\mathrm{C}$ show the results for the SVI-return, the SVI-volatility, and the SVI-abnormal trading volume, respectively. ${ }^{*}{ }^{* *}$ and ${ }^{* * *}$ denote the $10 \%, 5 \%$, and $1 \%$ significance levels, respectively.

14 http://www.internetlivestats.com/internet-users-by-country/. 
Table 2. Panel vector autoregression (VAR) estimations.

\begin{tabular}{|c|c|c|c|c|c|c|}
\hline \multicolumn{7}{|c|}{ Panel A: SVI and Return. } \\
\hline & \multicolumn{2}{|c|}{ Full Sample } & \multicolumn{2}{|c|}{ Developed Markets } & \multicolumn{2}{|c|}{ Developing Markets } \\
\hline & $S V I_{t}$ & $R_{t}$ & $S V I_{t}$ & $\boldsymbol{R}_{t}$ & $S V I_{t}$ & $R_{t}$ \\
\hline$S V I_{t-1}$ & $\begin{array}{c}0.7512 * * * \\
(0.0588)\end{array}$ & $\begin{array}{c}-0.0035 * * * \\
(0.0014)\end{array}$ & $\begin{array}{c}0.8790^{* * *} \\
(0.0583)\end{array}$ & $\begin{array}{l}-0.0041 \\
(0.0018)\end{array}$ & $\begin{array}{c}0.6753 * * * \\
(0.0872)\end{array}$ & $\begin{array}{l}-0.0026 \\
(0.0026)\end{array}$ \\
\hline$R_{t-1}$ & $\begin{array}{c}-1.8397^{* * *} \\
(0.9379)\end{array}$ & $\begin{array}{c}-0.0534 \text { ** } \\
(0.0224)\end{array}$ & $\begin{array}{c}-2.0877^{*} \\
(1.1872)\end{array}$ & $\begin{array}{l}-0.0411 \\
(0.0352)\end{array}$ & $\begin{array}{l}-0.0701 \\
(1.0598)\end{array}$ & $\begin{array}{l}-0.0493 \\
(0.0496)\end{array}$ \\
\hline Hansen $J$ Test & \multicolumn{2}{|c|}{0.168} & \multicolumn{2}{|c|}{0.127} & \multicolumn{2}{|c|}{0.990} \\
\hline \multicolumn{7}{|c|}{ Panel B: SVI and Volatility. } \\
\hline & \multicolumn{2}{|c|}{ Full Sample } & \multicolumn{2}{|c|}{ Developed Markets } & \multicolumn{2}{|c|}{ Developing Markets } \\
\hline & $S V I_{t}$ & $\sigma_{t}^{2}$ & $S V I_{t}$ & $\sigma_{t}^{2}$ & $S V I_{t}$ & $\sigma_{t}^{2}$ \\
\hline$S V I_{t-1}$ & $\begin{array}{c}0.5861 * * * \\
(0.0624)\end{array}$ & $\begin{array}{c}0.0000 \\
(0.0001)\end{array}$ & $\begin{array}{c}0.7683^{* * *} \\
(0.0769)\end{array}$ & $\begin{array}{c}0.0000 \\
(0.0001)\end{array}$ & $\begin{array}{c}0.5299 * * * \\
(0.0817)\end{array}$ & $\begin{array}{l}-0.0000 \\
(0.0001)\end{array}$ \\
\hline$S V I_{t-2}$ & $\begin{array}{c}0.2436^{* * *} \\
(0.0610)\end{array}$ & $\begin{array}{l}0.0002 * * \\
(0.0001)\end{array}$ & $\begin{array}{c}0.1643 * * \\
(0.0693)\end{array}$ & $\begin{array}{c}0.0001 \\
(0.0001)\end{array}$ & $\begin{array}{c}0.1726^{* *} \\
(0.0797)\end{array}$ & $\begin{array}{l}0.0002^{*} \\
(0.0001)\end{array}$ \\
\hline$\sigma_{t-1}^{2}$ & $\begin{array}{l}28.6188 * \\
(17.0147)\end{array}$ & $\begin{array}{c}0.4334^{* * *} \\
(0.0817)\end{array}$ & $\begin{array}{c}49.8386^{* * *} \\
(17.1577)\end{array}$ & $\begin{array}{c}0.5011^{* * *} \\
(0.0852)\end{array}$ & $\begin{array}{l}-9.2805 \\
(6.6255)\end{array}$ & $\begin{array}{c}0.3144^{* * *} \\
(0.1016)\end{array}$ \\
\hline$\sigma_{t-2}^{2}$ & $\begin{array}{c}8.7659 \\
(9.3922) \\
\end{array}$ & $\begin{array}{c}0.2885^{* * *} \\
(0.0548)\end{array}$ & $\begin{array}{c}9.4705 \\
(9.2032)\end{array}$ & $\begin{array}{c}0.1961^{* * *} \\
(0.0535)\end{array}$ & $\begin{array}{c}3.5395 \\
(16.8600)\end{array}$ & $\begin{array}{l}0.1244^{* *} \\
(0.0494)\end{array}$ \\
\hline Hansen $J$ Test & \multicolumn{2}{|c|}{0.888} & \multicolumn{2}{|c|}{0.584} & \multicolumn{2}{|c|}{0.998} \\
\hline \multicolumn{7}{|c|}{ Panel C: SVI and Abnormal Trading Volume. } \\
\hline & \multicolumn{2}{|c|}{ Full Sample } & \multicolumn{2}{|c|}{ Developed Markets } & \multicolumn{2}{|c|}{ Developing Markets } \\
\hline & $S V I_{t}$ & $A T V_{t}$ & $S V I_{t}$ & $S V I_{t}$ & $A T V_{t}$ & $S V I_{t}$ \\
\hline$S V I_{t-1}$ & $\begin{array}{c}0.5687 * * * \\
(0.0419)\end{array}$ & $\begin{array}{c}0.0022 \\
(0.0021) \\
\end{array}$ & $\begin{array}{c}0.5632 * * * \\
(0.0580)\end{array}$ & $\begin{array}{l}-0.0023 \\
(0.0019)\end{array}$ & $\begin{array}{c}0.5938 * * * \\
(0.0529)\end{array}$ & $\begin{array}{c}0.0001 \\
(0.0020)\end{array}$ \\
\hline$S V I_{t-2}$ & $\begin{array}{c}0.2178^{* * *} \\
(0.0392)\end{array}$ & $\begin{array}{c}0.0001 \\
(0.0017) \\
\end{array}$ & $\begin{array}{c}0.2887^{* * *} \\
(0.0558)\end{array}$ & $\begin{array}{c}0.0037^{* *} \\
(0.0016)\end{array}$ & $\begin{array}{c}0.1695 * * * \\
(0.0503)\end{array}$ & $\begin{array}{c}0.0034^{* *} \\
(0.0016)\end{array}$ \\
\hline$A T V_{t-1}$ & $\begin{array}{c}2.5403 * * * \\
(0.2191)\end{array}$ & $\begin{array}{c}0.7262 * * * \\
(0.0514)\end{array}$ & $\begin{array}{c}4.4586^{* * *} \\
(0.8500)\end{array}$ & $\begin{array}{c}1.2674 * * * \\
(0.0784)\end{array}$ & $\begin{array}{c}0.5779 * * * \\
(0.1134)\end{array}$ & $\begin{array}{c}0.5282 * * * \\
(0.0660)\end{array}$ \\
\hline$A T V_{t-2}$ & $\begin{array}{c}-0.5859^{* * *} \\
(0.0845)\end{array}$ & $\begin{array}{c}0.2207^{* * *} \\
(0.0449)\end{array}$ & $\begin{array}{c}-3.9262 * * * \\
(0.7693)\end{array}$ & $\begin{array}{c}-0.2962 * * * \\
(0.0694)\end{array}$ & $\begin{array}{c}1.1878^{* * *} \\
(0.1898)\end{array}$ & $\begin{array}{c}0.4054^{* * *} \\
(0.0636)\end{array}$ \\
\hline Hansen $J$ Test & \multicolumn{2}{|c|}{0.631} & \multicolumn{2}{|c|}{0.931} & \multicolumn{2}{|c|}{0.637} \\
\hline
\end{tabular}

Panels A to C of Table 2 show the panel VAR estimations of relationships between the SVI and stock market indices, the SVI and stock market volatilities, and the SVI and market abnormal trading volumes, respectively. The minimum consenting MMSC-AIC, MMSC-BIC, and MMSC-HQIC optimal lag length, which is equal to one for the SVI-return relationship and two for the SVI-volatility and the SVI-abnormal volume relationships. Hansen $J$ test tells about over-identification restrictions of the GMM estimation. Standard errors are shown in parentheses. ${ }^{*}, * *$ and ${ }^{* * *}$ denote the $10 \%, 5 \%$, and $1 \%$ significance levels, respectively.

Panel B of Table 2 presents the results of the full sample for the SVI-volatility relationship. As in the SVI-return relationship, we find lagged volatilities had impacts on the current SVI and vice versa. ${ }^{15}$ Again, the impact of the volatility was larger than that of SVI, but the relationship between the SVI and volatility was positive. The search intensity was one of the key determinants of market volatility. Interestingly, past volatilities of the market called for market-wide attention in the developed markets, but not vice versa. This confirms that investors are more concerned about large price movements due to heightened uncertainty. Surprisingly, the volatility effect did not play a role in the developing markets, but the search intensities did. The higher the search intensity in the past, the more volatile the market. Searching information by retail investors caused noises to the market. Again, we did not

15 Examples of a linkage between information and volatility in FX markets include Treepongkaruna and Gray (2009) and Treepongkaruna et al. (2012). 
observe a strong SVI-volatility relationship in the developing markets. The difference in results of the relationships between the developed and developing markets could be explained as follows. Similar to the argument put forward in the SVI-return relationship, we argue that Asians are less analytic, less rational, and more holistic than Westerners (Nisbett et al. 2001).

For developing countries, investing in stock markets is more likely to be a gamble than investment. Thus, they do not care about the variability in the stock markets. Kumar (2009), studying the tendency to gamble and trading decisions supports this statement. Low-income investors (i.e., retail investors in developing markets) prefer trading in lottery-type stocks and the level of investing in lottery-type stock is higher in markets in which traders like to trade them. Finally, developing markets have different market microstructures compared to developed markets (Madhavan 2000).

Compared with the other relationships, Panel C of Table 2 indicates somewhat different results for the SVI-volume analyses. A weak relationship was noted for the full sample, where only abnormal trading volumes in the past influenced the current SVI. In contrast, strong evidence was observed in both developed and developing countries, where abnormal trading volumes had impacts on the current SVI and vice versa. Moreover, the effects of abnormal trading volume dominated those of SVI in all cases. It seemed that trading volume showed a strong connection with the SVI. This was consistent with the prior literature (Barber and Odean 2008 and Gervais et al. 2001) that uses the trading volumes as a proxy of investor attention. A logical explanation is that investors pay more attention on their interesting stocks and have a large tendency to trade them. Thus, the trading volume is more closely related to attention. In other words, without attention, trading volumes cannot emerge.

In sum, the dynamic interrelationships between investor attention and stock market activities were more prominent in the developed countries than in the developing countries. Our findings were attributed to behavioral biases, for instance Hou et al. (2009) document that over-reaction is the result of the attention. Without attention, investors cannot process and over-react to available information. Weak evidence on the developing countries showed that people do not search for information before they decide to trade, in contrast to the suggestion of Merton (1987).

Additionally, we present the impulse response functions for the three models employed in this study in Figure 1. As usual, Panels A to C depict the impulse responses of the SVI-return, the SVI-volatility, and the SVI-volume relationships, respectively. The impulse response function was estimated by employing the Cholesky decomposition (Sim 1980). The $5 \%$ error bands were created by using 500 repetitions of a Monte Carlo simulation. In general, the impulse responses were consistent with the panel VAR estimated coefficients and most of them showed pulse-like lines, which tended to reverse within five weeks for the return relationship and within ten weeks for the volatility and trading volume. Shocks in returns seemed to have a lower effect than the other two cases. Thus, stock markets were more efficient in terms of return than volatility and trading volumes. The responses of the SVI to return and those of the return to SVI were negative for all cases as depicted in Panel A. This was consistent with the prior literature that shows a dynamic interdependence relationship between the SVI and stock market index returns. However, a different pattern was present in the relationship between the SVI and stock index volatility as depicted in Panel B and the SVI and abnormal trading volume as depicted in Panel C, respectively. The impulse responses of the SVI to volatility and those of the volatility to SVI were positive, hence a shock in the SVI (volatility) increased the stock market index volatility (SVI). This pattern was similar to the SVI-abnormal trading volume relationship. Thus, a shock in SVI increased trading volumes and vice versa, which supports prior studies (Barber and Odean 2008 and Gervais et al. 2001) using trading volume a proxy of investor attention. 


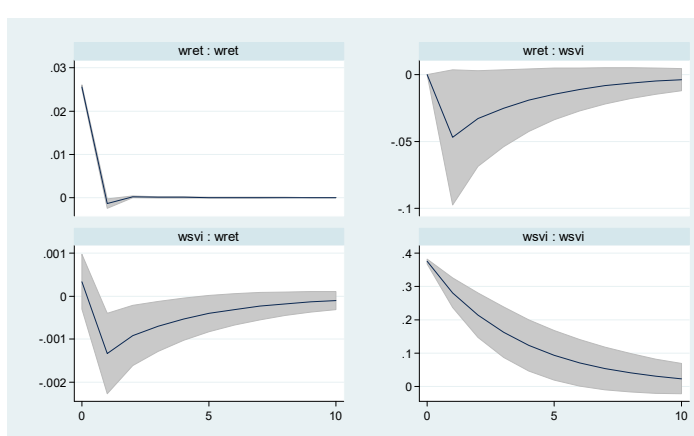

All Countries
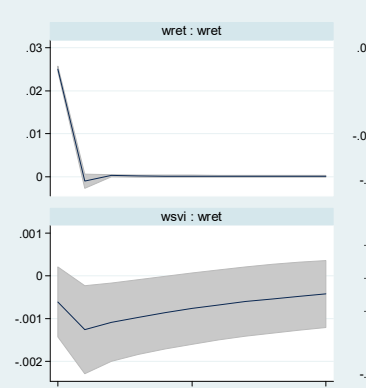

Developed Countrie

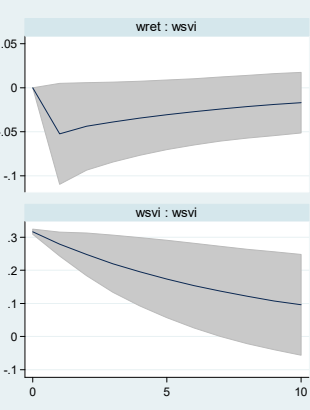

Orthogonalized IRF

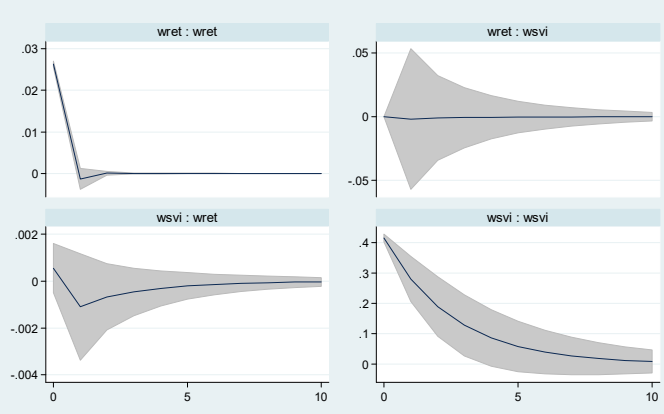

Developing Countries

impulse : response

(A) SVI and Return.

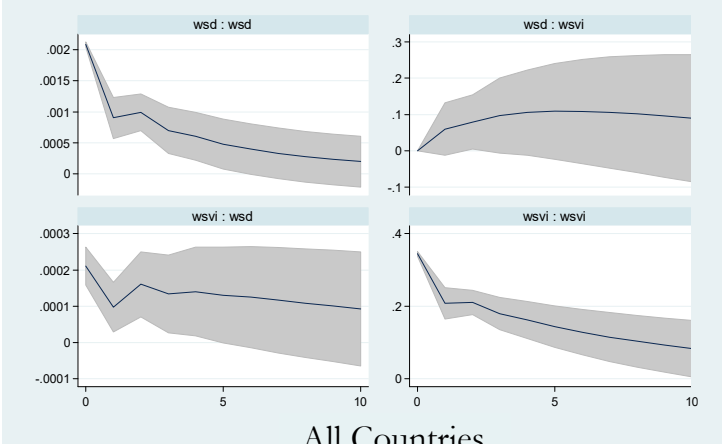

All Countries
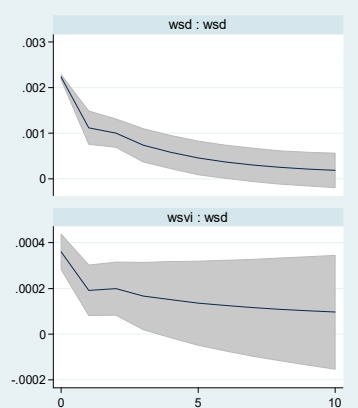

Developed Countries
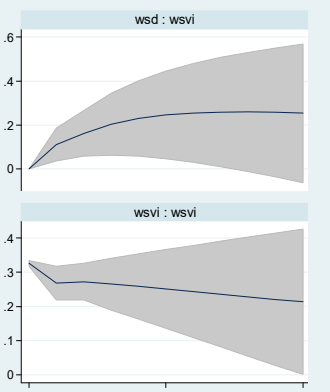
- Orthogonalized IRF

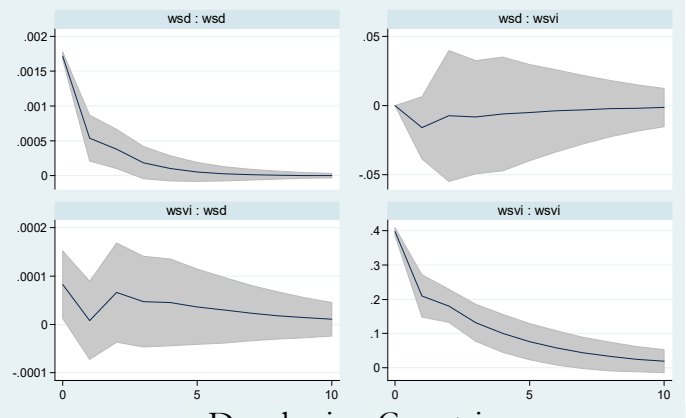

Developing Countries

impulse : response

$$
95 \% \mathrm{Cl}
$$

(B) SVI and Volatility.

\section{Figure 1. Cont.}




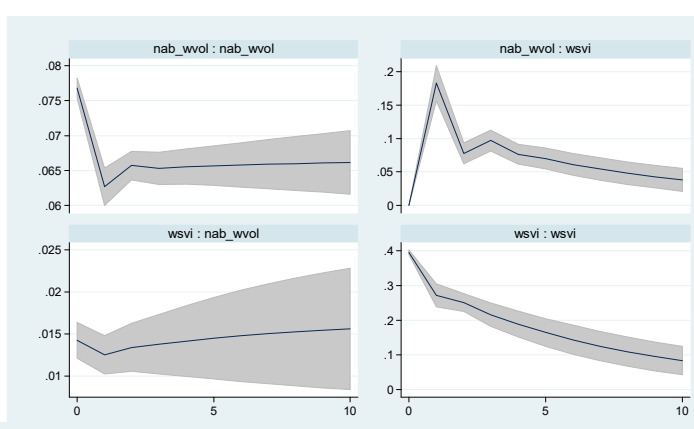

All Countries

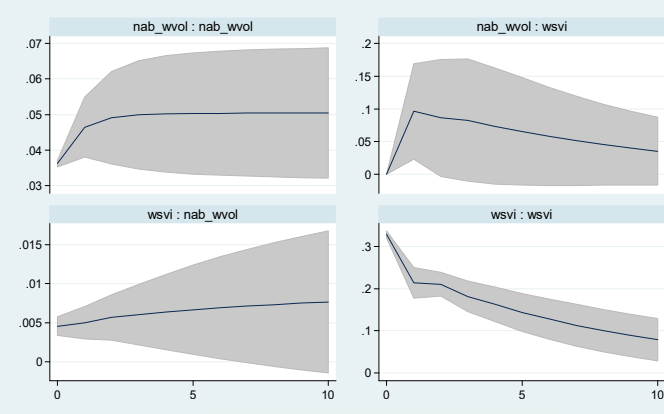

Developed Countries

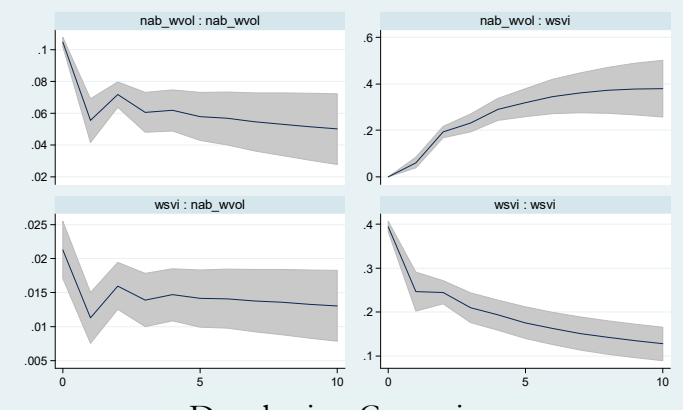

Developing Countries

impulse : response

$95 \% \mathrm{Cl} \longrightarrow$ Orthogonalized IRF

(C) SVI and Abnormal Volume.

Figure 1. Orthogonalized impulse responses for the SVI relationships. Figure 1 depicts the impulse responses for the SVI-return (A), the SVI-volatility (B), and the SVI-abnormal trading volumes (C), respectively. From the left to right, each figure represents the impulse responses of the full sample, developed countries, and developing countries. The $95 \%$ confidence interval (CI) is created by the Monte Carlo simulation with 500 repetitions. 


\subsection{Variance Decomposition}

A variance decomposition showed the accumulated impact of the shock on one variable to the proportion of variation in a given variable. Table 3 presents the forecast-error variance decomposition for all relationships in the three cases. Panel A reports the variance decomposition of the SVI-return relationship. We found that returns explain the variation in SVI approximately to be $1.33 \%$ for the full sample and $2.00 \%$ for developed countries of total variations for ten periods ahead, respectively. The effect in the developing countries was very small, which is consistent with our finding on the non-existent SVI-return relationship. Moreover, the effects of the SVI on the return variation were small for all cases. The effects of the volatility on the shock in the SVI were more pronounced than that in the SVI-return relationship, as shown in Panel A. This was true for the cases of the developed and developing countries. The effects of the abnormal trading volume on the shock in the SVI were the largest, accounting for almost 50\% variation. Again, the trading volume was a good proxy of investor attention and showed interdependence relationship.

Table 3. Variance decomposition.

\begin{tabular}{|c|c|c|c|c|c|c|c|}
\hline \multicolumn{8}{|c|}{ Panel A: SVI and Return. } \\
\hline \multirow{3}{*}{$\begin{array}{c}\text { Response } \\
\text { Variable }\end{array}$} & \multirow{3}{*}{$\begin{array}{l}\text { Forecast } \\
\text { Horizon }\end{array}$} & \multicolumn{6}{|c|}{ Impulse Variable } \\
\hline & & \multicolumn{2}{|c|}{ Full Sample } & \multicolumn{2}{|c|}{ Developed Countries } & \multicolumn{2}{|c|}{ Developing Countries } \\
\hline & & SVI & Return & SVI & Return & SVI & Return \\
\hline \multirow[t]{10}{*}{ SVI } & 1 & 1.0000 & 0.0000 & 1.0000 & 0.0000 & 1.0000 & 0.0000 \\
\hline & 2 & 0.9901 & 0.0099 & 0.9848 & 0.0152 & 1.0000 & 0.0000 \\
\hline & 3 & 0.9878 & 0.0122 & 0.9809 & 0.0191 & 1.0000 & 0.0000 \\
\hline & 4 & 0.9868 & 0.0132 & 0.9789 & 0.0211 & 1.0000 & 0.0000 \\
\hline & 5 & 0.9863 & 0.0137 & 0.9778 & 0.0222 & 1.0000 & 0.0000 \\
\hline & 6 & 0.9860 & 0.0140 & 0.9771 & 0.0229 & 1.0000 & 0.0000 \\
\hline & 7 & 0.9859 & 0.0141 & 0.9766 & 0.0234 & 1.0000 & 0.0000 \\
\hline & 8 & 0.9858 & 0.0142 & 0.9762 & 0.0238 & 1.0000 & 0.0000 \\
\hline & 9 & 0.9857 & 0.0143 & 0.9760 & 0.0240 & 1.0000 & 0.0000 \\
\hline & 10 & 0.9857 & 0.0143 & 0.9758 & 0.0242 & 1.0000 & 0.0000 \\
\hline \multirow[t]{10}{*}{ Return } & 1 & 0.0002 & 0.9998 & 0.0006 & 0.9994 & 0.0004 & 0.9996 \\
\hline & 2 & 0.0029 & 0.9971 & 0.0031 & 0.9969 & 0.0022 & 0.9978 \\
\hline & 3 & 0.0041 & 0.9959 & 0.0049 & 0.9951 & 0.0028 & 0.9972 \\
\hline & 4 & 0.0049 & 0.9951 & 0.0064 & 0.9936 & 0.0031 & 0.9969 \\
\hline & 5 & 0.0053 & 0.9947 & 0.0075 & 0.9925 & 0.0033 & 0.9967 \\
\hline & 6 & 0.0056 & 0.9944 & 0.0084 & 0.9916 & 0.0033 & 0.9967 \\
\hline & 7 & 0.0057 & 0.9943 & 0.0091 & 0.9909 & 0.0034 & 0.9966 \\
\hline & 8 & 0.0058 & 0.9942 & 0.0097 & 0.9903 & 0.0034 & 0.9966 \\
\hline & 9 & 0.0058 & 0.9942 & 0.0101 & 0.9899 & 0.0034 & 0.9966 \\
\hline & 10 & 0.0059 & 0.9941 & 0.0105 & 0.9895 & 0.0034 & 0.9966 \\
\hline \multicolumn{8}{|c|}{ Panel B: SVI and Volatility. } \\
\hline Response & Forecast & & & Impu & ariable & & \\
\hline \multirow[t]{2}{*}{ Variable } & Horizon & \multicolumn{2}{|c|}{ Full Sample } & \multicolumn{2}{|c|}{ Developed Countries } & \multicolumn{2}{|c|}{ Developing Countries } \\
\hline & & SVI & Volatility & SVI & Volatility & SVI & Volatility \\
\hline \multirow[t]{9}{*}{ SVI } & 1 & 1.0000 & 0.0000 & 1.0000 & 0.0000 & 1.0000 & 0.0000 \\
\hline & 2 & 0.9785 & 0.0215 & 0.9350 & 0.0650 & 0.9987 & 0.0013 \\
\hline & 3 & 0.9546 & 0.0454 & 0.8669 & 0.1331 & 0.9987 & 0.0013 \\
\hline & 4 & 0.9252 & 0.0748 & 0.8009 & 0.1991 & 0.9985 & 0.0015 \\
\hline & 5 & 0.8972 & 0.1028 & 0.7458 & 0.2542 & 0.9984 & 0.0016 \\
\hline & 6 & 0.8713 & 0.1287 & 0.7010 & 0.2990 & 0.9984 & 0.0016 \\
\hline & 7 & 0.8485 & 0.1516 & 0.6650 & 0.3350 & 0.9983 & 0.0017 \\
\hline & 8 & 0.8288 & 0.1712 & 0.6360 & 0.3640 & 0.9983 & 0.0017 \\
\hline & 9 & 0.8120 & 0.1880 & 0.6125 & 0.3875 & 0.9983 & 0.0017 \\
\hline
\end{tabular}


Table 3. Cont.

\begin{tabular}{|c|c|c|c|c|c|c|c|}
\hline \multicolumn{8}{|c|}{ Panel A: SVI and Return. } \\
\hline \multirow{3}{*}{$\begin{array}{c}\text { Response } \\
\text { Variable }\end{array}$} & \multirow{3}{*}{$\begin{array}{c}\text { Forecast } \\
\text { Horizon } \\
10\end{array}$} & \multicolumn{6}{|c|}{ Impulse Variable } \\
\hline & & \multicolumn{2}{|c|}{ Full Sample } & \multicolumn{2}{|c|}{ Developed Countries } & \multicolumn{2}{|c|}{ Developing Countries } \\
\hline & & 0.7980 & 0.2020 & 0.5934 & 0.4066 & 0.9983 & 0.0017 \\
\hline \multirow[t]{10}{*}{ Volatility } & 1 & 0.0101 & 0.9899 & 0.0252 & 0.9748 & 0.0023 & 0.9977 \\
\hline & 2 & 0.0103 & 0.9897 & 0.0259 & 0.9741 & 0.0021 & 0.9979 \\
\hline & 3 & 0.0128 & 0.9872 & 0.0275 & 0.9725 & 0.0033 & 0.9967 \\
\hline & 4 & 0.0145 & 0.9855 & 0.0290 & 0.9710 & 0.0039 & 0.9961 \\
\hline & 5 & 0.0165 & 0.9835 & 0.0305 & 0.9695 & 0.0045 & 0.9955 \\
\hline & 6 & 0.0182 & 0.9818 & 0.0318 & 0.9682 & 0.0048 & 0.9952 \\
\hline & 7 & 0.0199 & 0.9801 & 0.0330 & 0.9670 & 0.0051 & 0.9949 \\
\hline & 8 & 0.0213 & 0.9787 & 0.0341 & 0.9659 & 0.0052 & 0.9948 \\
\hline & 9 & 0.0226 & 0.9774 & 0.0352 & 0.9649 & 0.0053 & 0.9947 \\
\hline & 10 & 0.0237 & 0.9763 & 0.0361 & 0.9639 & 0.0054 & 0.9946 \\
\hline \multicolumn{8}{|c|}{ Panel C: SVI and Abnormal Trading Volume. } \\
\hline Response & Forecast & \multicolumn{6}{|c|}{ Impulse Variable } \\
\hline \multirow[t]{2}{*}{ Variable } & Horizon & \multicolumn{2}{|c|}{ Full Sample } & \multicolumn{2}{|c|}{ Developed Countries } & \multicolumn{2}{|c|}{ Developing Countries } \\
\hline & & SVI & Volume & SVI & Volume & SVI & Volume \\
\hline \multirow[t]{10}{*}{ SVI } & 1 & 1.0000 & 0.0000 & 1.0000 & 0.0000 & 1.0000 & 0.0000 \\
\hline & 2 & 0.8716 & 0.1284 & 0.9288 & 0.0712 & 0.9834 & 0.0166 \\
\hline & 3 & 0.8054 & 0.1946 & 0.8994 & 0.1006 & 0.8719 & 0.1281 \\
\hline & 4 & 0.7175 & 0.2825 & 0.8726 & 0.1274 & 0.7728 & 0.2272 \\
\hline & 5 & 0.6427 & 0.3573 & 0.8532 & 0.1468 & 0.6672 & 0.3328 \\
\hline & 6 & 0.5766 & 0.4234 & 0.8368 & 0.1632 & 0.5809 & 0.4191 \\
\hline & 7 & 0.5210 & 0.4790 & 0.8228 & 0.1772 & 0.5094 & 0.4906 \\
\hline & 8 & 0.4744 & 0.5256 & 0.8104 & 0.1896 & 0.4524 & 0.5476 \\
\hline & 9 & 0.4355 & 0.5645 & 0.7992 & 0.2008 & 0.4067 & 0.5933 \\
\hline & 10 & 0.4029 & 0.5971 & 0.7890 & 0.2110 & 0.3700 & 0.6300 \\
\hline \multirow[t]{10}{*}{ Volume } & 1 & 0.0515 & 0.9485 & 0.0298 & 0.9702 & 0.0396 & 0.9604 \\
\hline & 2 & 0.0539 & 0.9461 & 0.0252 & 0.9748 & 0.0397 & 0.9604 \\
\hline & 3 & 0.0558 & 0.9442 & 0.0264 & 0.9736 & 0.0417 & 0.9583 \\
\hline & 4 & 0.0575 & 0.9425 & 0.0282 & 0.9718 & 0.0430 & 0.9570 \\
\hline & 5 & 0.0589 & 0.9411 & 0.0304 & 0.9696 & 0.0446 & 0.9554 \\
\hline & 6 & 0.0603 & 0.9397 & 0.0326 & 0.9674 & 0.0459 & 0.9541 \\
\hline & 7 & 0.0615 & 0.9385 & 0.0349 & 0.9651 & 0.0471 & 0.9529 \\
\hline & 8 & 0.0626 & 0.9374 & 0.0371 & 0.9629 & 0.0482 & 0.9518 \\
\hline & 9 & 0.0636 & 0.9364 & 0.0392 & 0.9608 & 0.0491 & 0.9509 \\
\hline & 10 & 0.0644 & 0.9356 & 0.0412 & 0.9588 & 0.0500 & 0.9500 \\
\hline
\end{tabular}

Table 3 shows the variance decompositions of the relationships. Panels A to C show the proportion of the response variable explained by the shock of the impulse variable of the relationships between the SVI and stock market indices, the SVI and stock market volatilities, and the SVI and market abnormal trading volumes, respectively, in the next 10 periods.

\subsection{Developing and Developed Countries}

In order to investigate the difference in the SVI-return, the SVI-volatility, and the SVI-volume relationships between the developed and developing countries, we followed Love and Zicchino (2006) and Grossmann et al. (2014) by taking the difference in impulse responses of these two groups. Figure 2 depicts the impulse responses of the difference between developed and developing markets of all relationships. The significance of the difference in impulse responses was greater than $5 \%$. These findings confirm differences detected in developed and developing countries reported from our panel VAR analyses. 

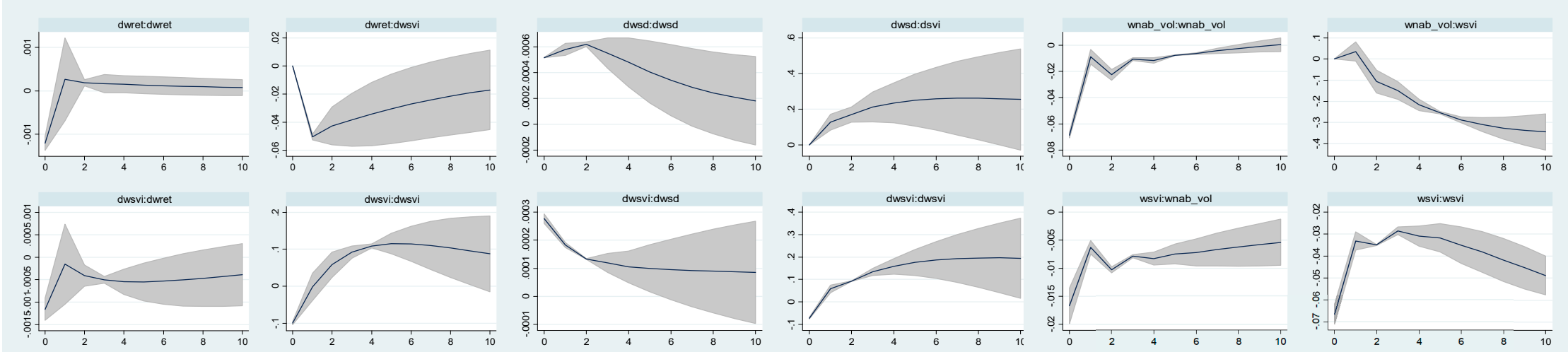

SVI and Return

SVI and Volatility

SVI and Abnormal Trading Volume

$95 \% \mathrm{Cl}$

Orthogonalized IRF

impulse : response

Figure 2. Orthogonalized impulse response for the difference between developed and developing markets. Figure 2 depicts the impulse response function of the difference between the developed and developing markets in three relationships. 


\section{Conclusions}

In this study, we examine the role of investor attention in stock markets. Google SVI is chosen as a proxy of retail investor attention with stock market activities, i.e., market return, market volatility, and market abnormal trading volume. We apply a new methodology, the panel vector autoregressive model, to investigate these relationships. This technique is superior to other techniques commonly employed in the existing literature, as it takes into account of both the fixed and the time-varying effects. Employing panel VAR addresses concerns raised in Tantaopas et al. (2016) that attention behavior might be different in each country due to differences the shareholder base, culture, ownership structure, legal protection, law enforcement, and financial education.

After controlling for both fixed and time-varying effects, we find general support for prior evidence that investor attention is related to the returns, volatility, and trading volume. However, our results shed a new light on multi-country analyses as follows. We observe mostly two-way panel Granger causality in all relationships, though the weakest relationship is detected in the developing countries. These findings are reconfirmed by the panel VAR analyses, indicating dynamic and interdependent relationships. However, for both SVI-return and SVI-volatility relationships, we find the negative impact on the SVI is greater than that of the SVI on return or volatility. The investor attention-abnormal trading volume relationship is mixed but statistically significant in all cases. To investigate the different level of investor attention between developing and developed markets, we employ and take the difference of the impulse response functions between these two groups and find that the attention is statistically significantly different. Thus, we conclude that investor attention is necessary for equity markets, but the effect is different between developed and developing countries. An interrelation among all stock market activities and investor attention is left for future research.

Author Contributions: The contribution to this article is distributed as follows: C.P. $65 \%$, S.T. $20 \%$ and R.B. $15 \%$.

Funding: Chaiyuth Padungsaksawasdi acknowledges financial support from the Business Research Center of the Thammasat Business School.

Acknowledgments: We thank the editor and the anonymous referee for their suggestion. We benefit from the discussants and the seminar participants at the Finance Research Workshop, Department of Finance, Thammasat Business School, the 2016 Paris Financial Management Conference, and the 24th annual conference of the Multinational Finance Society, Bucharest, Romania. We are grateful to Tatre Jantarakolica for support and comment. We thank Phenpimol Boonbundanrit, Jutamas Wongkantarakorn, and Phasin Wanidwaranan for their excellent research assistance.

Conflicts of Interest: The author declares no conflict of interest.

\section{Appendix A}

Table A1. Google search keywords for stock market indices.

\begin{tabular}{cc}
\hline Country & Google Search Keyword \\
\hline Developing countries & \\
China & shanghai_stock_exchange \\
India & bse \\
Malaysia & klse \\
Thailand & set_50 \\
Developed countries & \\
Australia & asx_200 \\
Hong Kong & hsi \\
Japan & nikkei \\
Korea & kospi \\
New Zealand & nzx \\
Singapore & straits_times \\
\hline
\end{tabular}




\section{References}

Al-Eroud, Ahmed F., Mohammad A. Al-Ramahi, Mohammad N. Al-Kabi, Izzat M. Alsmadi, and Emad M. Al-Shawakfa. 2011. Evaluating Google queries based on language preferences. Journal of Information Science 37: 282-92. [CrossRef]

Andrei, Daniel, and Michael Hasler. 2015. Investor attention and stock market volatility. The Review of Financial Studies 28: 33-72. [CrossRef]

Andrews, Donald W. K., and Biao Lu. 2001. Consistent model and moment selection procedures for GMM estimation with application to dynamic panel data models. Journal of Econometrics 101: 123-64. [CrossRef]

Ang, Andrew, Joseph Chen, and Yuhang Xing. 2006. Downside risk. The Review of Financial Studies 19: 1191-239. [CrossRef]

Aouadi, Amal, Mohamed Arouri, and Frédéric Teulon. 2013. Investor attention and stock market activity: Evidence from France. Economic Modelling 35: 674-81. [CrossRef]

Arellano, Manuel, and Olympia Bover. 1995. Another look at the instrumental variable estimation of error-components models. Journal of Econometrics 68: 29-51. [CrossRef]

Bank, Matthias, Martin Larch, and Georg Perter. 2011. Google search volume and its influence on liquidity and returns of German stocks. Financial Market Portfolio Management 25: 239-64. [CrossRef]

Barber, Brad M., and Terrance Odean. 2008. All that glitters: the effect of attention of attention and news on the buying behavior of individual and institutional investors. The Review of Financial Studies 21: 785-818. [CrossRef]

Benson, Karen, Robert Faff, and Tom Smith. 2014. Fifty years of finance research in the Asia Pacific Basin. Accounting \& Finance 54: 335-63.

Bijl, Laurens, Glenn Kringhaug, Polar Molnár, and Eirik Sandvik. 2016. Google searches and stock returns. International Review of Financial Analysis 45: 150-56. [CrossRef]

Boduroglu, Aysecan, Priti Shah, and Richard E. Nisbett. 2009. Cultural differences in allocation of attention in visual information processing. Journal of Cross Cultural Psychology 40: 349-60. [CrossRef] [PubMed]

Braun, Nicole. 2016. Google search volume sentiment and its impact on REIT market movements. Journal of Property Investment $\mathcal{E}$ Finance 34: 249-62.

Chang, Eric C., Joseph W. Cheng, and Ajay Khorana. 2000. An examination of herd behavior in equity markets: An international perspective. Journal of Banking and Finance 24: 1651-79. [CrossRef]

Chiang, Thomas C., and Dazhi Zheng. 2010. An empirical analysis of herd behavior in global stock markets. Journal of Banking \& Finance 34: 1911-21.

Choi, In. 2001. Unit root tests for panel data. Journal of International Money and Finance 20: 249-72. [CrossRef]

Da, Zhi, Joseph Engelberg, and Pengjie Gao. 2011. In search of attention. The Journal of Finance 66: 1461-99. [CrossRef]

Da, Zhi, Umit G. Gurun, and Mitch Warachka. 2014. Frog in the pan: continuous information and momentum. The Review of Financial Studies 27: 2171-218. [CrossRef]

DellaVigna, Stefano, and Joshua M. Pollet. 2009. Investor inattention and Friday earnings announcements. The Journal of Finance 64: 709-49. [CrossRef]

Dimpfl, Thomas, and Stephan Jank. 2016. Can Internet Search Queries Help to Predict Stock Market Volatility? European Financial Management 22: 171-92. [CrossRef]

Ding, Rong, and Wenxuan Hou. 2015. Retail investor attention and stock liquidity. Journal of International Financial Markets, Institutions \& Money 37: 12-26.

Do, Hung Xuan, Robert Brooks, Sirimon Treepongkaruna, and Eliza Wu. 2014. How does trading volume affect financial return distributions? International Review of Financial Analysis 35: 190-206. [CrossRef]

Gao, Zhenyu, Haohan Ren, and Bohui Zhang. 2016. Googling Investor Sentiment around the World. Journal of Financial and Quantitative Analysis, 1-66. [CrossRef]

Gervais, Simon, Ron Kaniel, and Dan H. Mingelgrin. 2001. The high-volume return premium. The Journal of Finance 61: 877-919. [CrossRef]

Goddard, John, Arben Kita, and Qingwei Wang. 2015. Investor attention and FX market volatility. Journal of International Financial Markets \& Institutions \& Money 38: 79-96.

Grossmann, Axel, Inessa Love, and Alexei G. Orlov. 2014. The dynamics of exchange rate volatility: A panel VAR approach. Journal of International Financial Markets, Institutions \& Money 33: 1-27. 
Hamid, Alain, and Moritz Heiden. 2015. Forecasting volatility with empirical similarity and Google trends. Journal of Economic Behavior E Organization 117: 62-81.

Harding, Noel, and Wen He. 2016. Investor mood and the determinants of stock prices: An experimental analysis. Accounting $\mathcal{E}$ Finance 56: 445-78.

Hayakawa, Kazuhiko. 2009. First difference or forward orthogonal deviation-which transformation should be used in dynamic panel data models? A simulation study. Economics Bulletin 29: 2008-17.

Holtz-Eakin, Douglas, Whitney Newey, and Harvey S. Rosen. 1988. Estimated vector autoregressions with panel data. Econometrica 56: 1371-95. [CrossRef]

Hou, Kewei, Wei Xiong, and Lin Peng. 2009. A Tale of Two Anomalies: The Implications of Investor Attention for Price and Earnings Momentum. SSRN Working Paper. Amsterdam: Elsevier.

Huberman, Gur, and Tomer Regev. 2001. Contagious speculation and a cure for cancer: A nonevent that made stock prices soar. The Journal of Finance 56: 387-96. [CrossRef]

Jacobs, Heiko. 2015. The role of attention constraints for investor behavior and economic aggregates: What have we learnt so far? Management Review Quarterly 65: 217-37. [CrossRef]

Johnman, Mark, Bruce James Vanstone, and Adrian Gepp. 2018. Predicting FTSE 100 returns and volatility using sentimental analysis. Accounting \& Finance 58: 253-74.

Joseph, Kissan, M. Babajide Wintoki, and Zelin Zhang. 2011. Forecasting abnormal stock returns and trading volume using investor sentiment: Evidence from online search. International Journal of Forecasting 27: 1116-27. [CrossRef]

Kahneman, Daniel. 1973. Attention and Effort. Englewood Cliffs: Princeton Hall.

Kumar, Alok. 2009. Who Gambles in the Stock Market? The Journal of Finance 64: 1889-933. [CrossRef]

Kumar, Alok, and Charles M. C. Lee. 2006. Retail Investor Sentiment and Return Comovements. The Journal of Finance 61: 2451-86. [CrossRef]

Laksomya, Nattapong, John G. Powell, Suparatana Tanthanongsakkun, and Sirimon Treepongkaruna. 2018. Are Internet message boards used to facilitate stock price manipulation? evidence from an emerging market, Thailand. Accounting $\mathcal{E}$ Finance 58: 275-309.

Li, Xin, Jian Ma, Shouyang Wang, and Xun Zhang. 2015. How does Google search affect trader positions and crude oil prices? Economic Modelling 49: 162-71. [CrossRef]

Love, Inessa, and Lea Zicchino. 2006. Financial development and dynamic investment behavior: Evidence from panel VAR. The Quarterly Review of Economics and Finance 46: 190-210. [CrossRef]

Madhavan, Ananth. 2000. Market microstructure: A survey. Journal of Financial Markets 3: 205-58. [CrossRef]

Merton, Robert C. 1987. A simple model of capital market equilibrium with incomplete information. The Journal of Finance 42: 483-510. [CrossRef]

Miller, Edward M. 1977. Risk, uncertainty, and divergence of opinion. The Journal of Finance 32: 1151-68. [CrossRef]

Nisbett, Richard E., Kaiping Peng, Incheol Choi, and Ara Norenzayan. 2001. Culture and systems of thought: holistic versus analytic cognition. Psychological Review 108: 291-310. [CrossRef] [PubMed]

Peng, Lin, Wei Xiong, and Tim Bollerslev. 2007. Investor attention and time-varying comovements. European Financial Management 13: 394-422. [CrossRef]

Piccoli, Pedro, Newton C. A. da Costa Jr., Wesley Vieira da Silva, and June A. W. Cruz. 2018. Investor sentiment and the risk-return tradeoff in the Brazilian market. Accounting $\mathcal{E}$ Finance 58: 599-618.

Rochdi, Karim, and Marian Dietzel. 2015. Outperforming the benchmark: Online information demand and REIT market performance. Journal of Property Investment E Finance 33: 169-95.

Rousseau, P. L., and P. Wachtel. 2000. Equity markets and growth: Cross-country evidence on timing and outcomes, 1980-1995. Journal of Banking and Finance 24: 1933-57. [CrossRef]

Sim, Christopher A. 1980. Macroeconomics and reality. Econometrica 48: 1-48.

Storms, Konstantin, Julia Kapraun, and Markus Rudolf. 2015. Can Retail Investor Attention Enhance Market Efficiency? Insights from Search Engine Data. SSRN Working Paper. Amsterdam: Elsevier.

Takeda, Fumiko, and Takumi Wakao. 2014. Google search intensity and its relationship with returns and trading volume of Japanese stocks. Pacific-Basin Finance Journal 27: 1-18. [CrossRef]

Tantaopas, Parkpoom, Chaiyuth Padungsaksawasdi, and Sirimon Treepongkaruna. 2016. Attention effect via internet search intensity in Asia-Pacific stock markets. Pacific-Basin Finance Journal 38: 107-24. [CrossRef]

Tourani-Rad, Alireza, and Stephen Kirkby. 2005. Investigation of investors' overconfidence, familiarity and socialization. Accounting E Finance 45: 283-300. 
Treepongkaruna, Sirimon, and Stephen Gray. 2009. Information and volatility links in the foreign exchange market. Accounting \& Finance 49: 385-405.

Treepongkaruna, Sirimon, Robert Brooks, and Stephen Gray. 2012. Do trading hours affect volatility links in the foreign exchange market? Australian Journal of Management 37: 7-27. [CrossRef]

Tsai, I.-Chun. 2017. Diffusion of optimistic and pessimistic investor sentiment: An empirical study of an emerging market. International Review of Economics and Finance 47: 22-34. [CrossRef]

Tsukioka, Yasutomo, Junya Yanagi, and Teruko Takada. 2017. Investor sentiment extracted from internet stock message boards and IPO puzzles. International Review of Economics and Finance 56: 205-17. [CrossRef]

Vozlyublennaia, Nadia. 2014. Investor attention, index performance, and return predictability. Journal of Banking and Finance 41: 17-35. [CrossRef]

Wang, Kemin, Xiaoyun Yu, and Bohui Zhang. 2017. The Power of the Passive Information Intermediary: Evidence from Google's China Exit. Working Paper. Available online: http://english.ckgsb.edu.cn/sites/default/files/ files/GoogleChina\%202017\%209\%204\%20cleaned_Xiaoyun\%20Yu.pdf (accessed on 4 September 2017).

Ying, Qianwei, Dongmin Kong, and Danglun Luo. 2015. Investor attention, institutional ownership, and stock return: empirical evidence from China. Emerging Markets Finance and Trade 51: 672-85. [CrossRef]

Yung, Kenneth, and Nadia Nafar. 2017. Investor attention and the expected returns of reits. International Review of Economics and Finance 48: 423-39. [CrossRef]

(C) 2019 by the authors. Licensee MDPI, Basel, Switzerland. This article is an open access article distributed under the terms and conditions of the Creative Commons Attribution (CC BY) license (http://creativecommons.org/licenses/by/4.0/). 